\title{
The Anthropological Consumption of Non-Human Primates, the Other Black Meat ${ }^{1}$
}

\author{
Reniel Rodríguez Ramos ${ }^{2}$
}

\begin{abstract}
The other has been the main staple consumed by the anthropological enterprise. One of the most succulent others consumed by anthropology has been the non-human primates. This work discusses the anthropological construction of primatological alterity as a tool for colonizing subaltern beings and peoples, using as heuristic mechanisms the temporalization of space and the naturalization of the other.
\end{abstract}

Key Words: Non-human primates, alterity, revisionist primatology, postcolonial anthropology

Anthropology has made its livelihood the construction of the other, since its main agenda has been to create a notion of the Western self based on its distinction from the rest of the creatures, both human and non-human (Haraway 1985, 2003, 2008). This "anthropophagous" discipline (Islam 2012) devised its otherness scale using as its baseline white male adults from Western societies to which the rest of humanity and the animal world has been weighed against to determine their degree of otherhood. One of these others used in anthropology has been the non-human primates (NHP), and their study has served a similar function in anthropology as non-Western (principally hunter-gather and other "traditional") societies, being both considered as subjects that provide indications of our pristine hominid state as well as our natural behavioral and organizational structure. In this sense, anthropologists have treated NHP as another "culture" created by an anthropologically motivated ethnogenetic process. Thus, similar parameters as those traditionally employed to create, study, and categorize other human cultures have also been applied to primates to justify the uniqueness of western humans within the natural and the cultural order. This has resulted in the concomitant cultural anthropologists' focus on "traditional" subalterns like the !Kung San of the Kalahari or the Mbuti of the Congo with the emphasis of anthropological primatologists to study other “ primate cultures" such as the chimpanzees (Pan spp.), gorillas (Gorilla spp.), and orangutans (Pongo spp.), among others.

Perceptions about what constitutes the other in anthropology have been defined along two major domains, which are not necessarily mutually exclusive: time (present/past) and space (the east/west dichotomy) (Fabian 1983). At the

\footnotetext{
${ }^{1}$ Received on April 23, 2014. Accepted on April 27, 2014. Last revisions received on May 5, 2014.

${ }^{2}$ Associate Professor, Programa de Ciencias Sociales, Universidad de Puerto Rico, Recinto de Utuado, Utuado, Puerto Rico 00641-2500. E-mail: renielrodriguez@gmail.com
}

DOI: 10.9784/LEB2(1)Rodriguez.01

Electronically available on May 16, 2014. Mailed on May 14, 2014. 
same time, other dualistic relationships have been tied up in this discourse: the black/white divide and the nature/culture metaphysic (Figure 1). These hierarchical and politically charged dichotomies have been used by anthropology since the start of the discipline as a tool of power, as one of the elements which has characterized it has been its ingrained colonialist conception of the domination of western (white-self) over non-western (black-other) societies and, in the same light, the supremacy of culture (West-self) over nature (non-Western-other) (Haraway 1978a, 1989). It is within this context that the politics involved in the study of non-human primates in anthropology were articulated and, with some fortunate variations, has persisted until this day. Unfortunately, however, those human and non-human that constitute the subject of study of anthropology have not necessarily received much benefit from the unsolicited intrusion into their lifeways, and thus in many cases the impact that these receive from these interventions has commonly outweighed the scientific retribution that has been gained from getting to know them to better know ourselves, as is clearly reflected by the sad example of Ota Benga which was at the core of the development of anthropology as a discipline (McCray 2012).

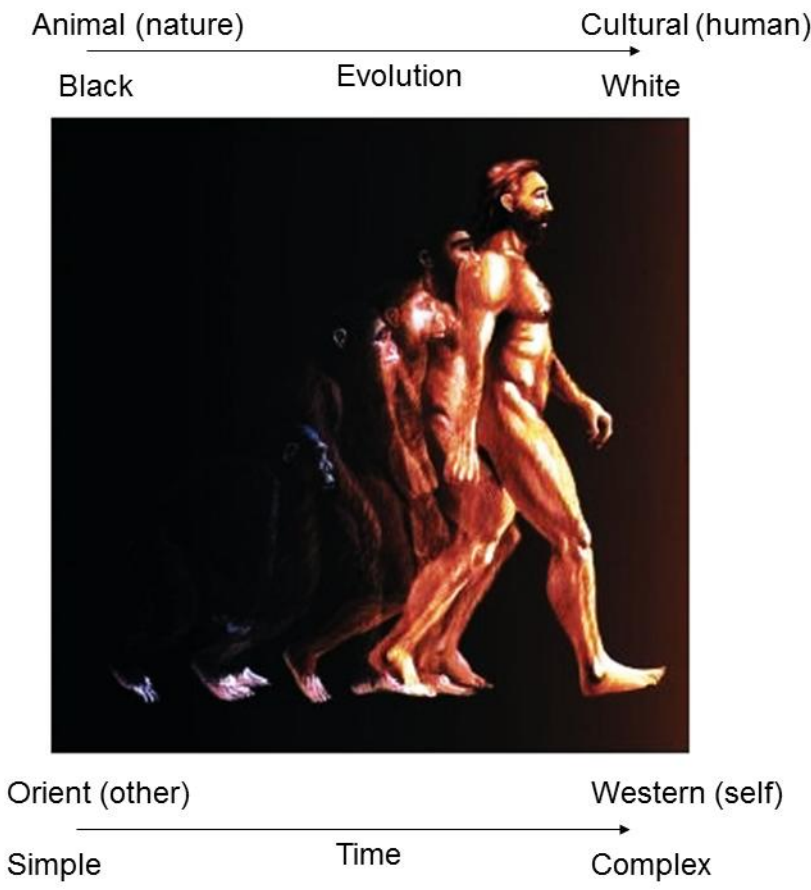

Figure 1. Temporalization and naturalization of the "other". Image modified from http://www.doeaccimphal.org.in/m18/file.php/1/final\%20contents/56/index.html; $\quad$ text added by the author. 
In this paper, I explore the metaphorical construction of non-human primates analogous to non-western cultures in anthropological discourse, and establish the uses and abuses to which these anthropological objects, as well as the rest of the "primitive" world, have been subjected within the discipline to through the use of temporalization and naturalization devises that have served to justify their consumption. It should be noted that I write this from the perspective of an archaeologist born and raised in an "eccentric context" (Pagán Jiménez 2004; Pagán Jiménez and Rodríguez Ramos 2008), who understands that in many ways the history of those creatures that inhabit nature mirrors that of us who still live in colonized territories, those who have been the meat consumed by the anthropological enterprise.

\section{The Temporalization of the Other}

Our modern conceptualization of time have had marked repercussions in the ways that anthropology has constructed the non-Western human and "animal" world. Modern concepts of secular time consider it as dimension that progress along a unidirectional, cumulative, and lineal axis (Bailey 1983). This vertical perception of progress through time has traditionally been tilted horizontally, thus leading to the equation of time with distance from the West and thus from "culture," resulting in the temporalization of space (Fabian 1983). In this sense, time was (and still is) used as a distancing device in the anthropological construction and classification of alterity, or otherness, which became the subject of study of the discipline since its onset. The spatio-temporal construction of alterity has been used by anthropologists to position the West with respect to the other, which also led to its manipulation as a tool to legitimize the colonialist enterprise that characterized the development of the discipline since its beginnings (Gosden 2004). Time is power and it has served as a control mechanism used to order non-Western peoples through the construction of their histories and in the justification for the exploitation of nature for enhancing our progress as the dominant species in the natural order (Fabian 1983).

This time perspectivism has also been translated in the construction of the "savage slot" (Trouillot 2003) as something old, and thus of the natural world as an entity that reflects the pristine conditions in which our early hominid ancestors lived. This progressive notion of time was related to the rise of evolutionary thought in anthropology in the first part of the $20^{\text {th }}$ century, in which views of NHP became tied with the articulation of a narrative of our progress along a unidirectional evolutionary vector which gradually separated us from the rest of those soulless creatures, as well as from the savages that inhabited the recondite jungle space. In this respect, NHP have been employed in a similar fashion as those other "primitive" cultures, as a "central iconography of the human past" (Sperling 1991:1), since they provide information of the ways of life of our hominid ancestors and of the innate structure that governs 
some of our behaviors. Louis Leakey used this perspective as one of the justifications for conducting studies on primates when he handpicked Biruté Galdikas-Bridanmour, Dian Fossey, and Jane Goodall to study orangutan, gorillas, and chimpanzees respectively. As noted by Hinde (1978:1; emphasis mine), who was Jane Goodall's dissertation chairman, the study of NHP would "not only help us gain a deeper understanding of Man himself and his origins, but also understand how and why he is like he is today."

Thus, at the onset of the discipline, especially after World War II, primate data was used in anthropology to understand the biological substratum that could condition some of our behaviors (Marcus 1990). Primatology was employed initially in anthropology in its physical subfield by concentrating on conducting morphological comparisons between NHP and the fossil hominid record in order to determine the ubiquity of physical parallelisms between the embryonic "us" and "them" (Schultz 1955). Later, the study of primates was fomented in order to explore their behaviors, which might help us gain a better understanding of those first chapters of the evolution of "Man" (Hinde 1978). More recently, studies on NHP as well as on other "simple" or "traditional" societies are still being focused on the reconstruction of human origins, using as tools theoretical frameworks such as behavioral ecology and sociobiology (e.g. Rodman 1999).

However, as has been noted in revisionist hunter-gather literature and historical anthropology, the use of NHP and "traditional" societies for modeling our past behaviors and natural structure has been based partly on the uniformitarian assumption that both of those analogs have not gone through any formation processes that have characterized the Western world and thus represent fossilized stages of evolution (i.e., Pompeii premise; Murray 1999). The selection of NHP and other "traditional" cultures as relevant analogies are primarily based on a typological notion of the chronos (Fabian 1983) in which space and time are merged into a single domain in order to illustrate our past living conditions and the laws that regulate our behaviors on the basis of the purported similarity of similar stages of evolution between them and our fossilized ancestors (Dunnell 1982). In this sense, the main emphasis has been placed on the synchronic relationship between analogous units rather than on their particular historical developments (Stahl 1993). This, however, has been considered by some to be totally misguided as it is now widely known that most of the "traditional" societies and NHP that are used as analogs have history, as these have gone through considerable transformations due to internal causes, and the marked environmental changes that have occurred over the millennia thus limiting their adequacy for reconstructing our human past (Stahl 1993). So, the notion of an unchanging nature used to justify the employment of NHP and "traditional" societies for modeling our evolutionary development and the structure of our present needs to be considered in more detail, as both of these have had a history which needs to be taken into consideration since it might be 
critical for, not only sorting out their alterations through time, but also for enhancing their survival in the future.

The artificial distance that was and still is created with this human and nonhuman other has also led to the view that the more distant from the anima urbis (Wolf 2002) the more natural, and thus older, it becomes. Thus, as will be noted in the next section, time becomes nature that becomes the other along a single, lineal vector.

\section{The Naturalization of the Other}

The spatio-temporal distance created between us and the human and nonhuman other that has been used in anthropology to justify them as subjects of study, has been partly based on creation of a "scientific" boundary between culture and nature. The construction of nature as the other's space has been used to facilitate the scientific classification of its inhabitants into the ordered taxonomies of "natural" categories used in the definition of non-Western cultures as well as the different types of NHP (Khalidi 1998). As previously noted, our construction of what is "natural" and thus what might be treated as other has been intimately related to the artificial temporal distance that has been created with nature. This separation, however, is almost inexistent for most other people who live in intimate relation with nature, who have long recognized the crosscutting relationship that we have with the rest of the creatures that inhabit in this planet (Lizarralde 2002). Despite this, such distance needs to be maintained in the anthropological discourse to justify the study of these others due to the basic subject-object dichotomy that is quasi-required in most of the scientific frameworks used today.

Not only the objective definition of who the other is, but also the delimitation of the space in which that other exists have also been naturalized in order to justify the imposition of Western cultural domination. Anthropology, and later primatology, was originally based on work conducted in non-Western countries, some of which were also the subject of the colonialist enterprise carried out by emerging empires, which were expanding their political and economic supremacy to extraneous terrains (Gosden 2004). These spaces outside the comforts of what used to be called the "First World" were culturally envisioned through a "darkening mirror" (Batiste 2012), depicting them as obscure (black) places full of chaos, mystery, and danger (i.e., "it's a jungle out there"). The nonhuman and non-Western human's world was treated as a big natural zoo where the beasts were uncaged and the people who lived there were envisioned as hordes of "faceless blobs" (Tringham 1991). In these spaces, the images of the Western explorers that went either to study the primitives (anthropologists), to study ruins of human's past (archaeologists), or to capture the creatures that lived in such world (western hunters) were basically indistinguishable from one another, and thus a public parallel was established between the different kaki-clothed "adventurers" (all compressed in the image of 
Indiana Jones) with the study of the primitive, dark, unknown, and dangerous. These were the spaces and the creatures that were to be understood to be conquered (i.e. consumed), and thus formed the basis for the anthropological enterprise.

The anthropological conception of the "natural" as a space to be conquered through its understanding (i.e., "what we don't know can hurt us") remained pivotal in the discipline. However, it began to be problematized in the anthropological arena in part with the advent of the feminist critique, which focused on the domination of the female body and its social manipulation for control purposes. This has led to the questioning of our view of the embodiment and engendering of the "natural" and the justifications that have been devised to legitimize its exploitation (Harraway 1978a, 1978b; Keane and Posergarten 2002). In this refiguring of the biological, feminist scholars have tried to unsettle the nature/culture divide and have looked at how such dichotomized relationship has been used to naturalize the social discourses, based on anthropologically derived "scientific" criteria, that justified the asymmetrical relations of power between the sexes and between the West (culture) and nature (non-Western contexts). As noted by Sperling (1991), with the use of data derived from studies on NHP male dominance became reasonable in its natural aim to organize and control women and the subaltern, as it formed part of their natural structure. In this sense, women became "nature," and their body became a space that was to be conquered, controlled, and exploited.

The engendering of nature as a space that can be dominated in a similar fashion as men have done (or tried to do) with women in most societies, has been considered by some to be one of the possible reasons for which some of the most famous representatives of this field are females. Perhaps, as noted by Harraway (1985:490), Leakey's selection of women for doing the fieldwork was due to the idea that "women's place is in the jungle," and while men went to conquer it women went to nurture its creatures (Fedigan 1994). This public perception of the nurturing woman primatologist is still highly pervasive, and perhaps might explain why Julia Roberts (instead of George Clooney) was sent to Borneo's jungle in order to care for some of its endangered creatures in the "documentary" The Animal Mind. And, interestingly enough, the number of women primatologists is on the rise. According to the figures of the American Society of Primatology (Shapiro 2003), around 58 percent of primatologists that are part of that association are women, and that number seems to be on a steady climb if we consider that of the 110 degrees given in primate-related studies in the last two decades of the last century, 90 (75 percent) were awarded to women, most of them graduated with terminal degrees in Anthropology. Furthermore, the current board of directors of the American Society of Primatologists (20122014) is composed exclusively of females. Whether this represents a subconscious reproduction of the previous conceptions of woman, the caretaker, 
as noted by Fedigan (1994) or is indicative of other gender-related factor deserves further scrutiny (Adessi et al. 2012).

\section{The Consumption of the Other}

The previously noted cannibalistic tendencies of anthropology have also entailed the naturalization of the other as a tool for facilitating its consumption, since the farther away that something is from culture the more natural it is and thus the more edible it becomes. The process of naturalizing the colonization of the other might be observed in different fashions. One of the main ways in which the West has canned the natural in order to consume it has been in the development of public displays of our human power over nature of which the most evident are the zoos. In these microcosms of the Noah's arc an attempt is made, not only to have a representative sample of those wild creatures which inhabit the dark spaces of nature, but also to demonstrate how we have the power to control its creatures by encasing them into squared prisons. This has been most eloquently expressed by Wolf (2002:723), who noted that in the construction of Australia's Adelaide Zoo “zoo practices consolidated and legitimated Australian colonial identity, naturalized colonial rule and oppression of indigenous peoples, and reinforced gendered and racialized biases of humananimal boundaries." These confinement spaces for animals have not only been used as displays of human power over nature, but also as images of the boundaries that humans have with the non-human and of our capacity of domesticating the other for our own benefits (Harraway 1985). The construction of zoos and the continuous search for animals for filling their cages have been justified primarily because of the educational role they play (Anderson 1995). However, the use of these spaces of animal suffering based on educational purposes is not justified, especially when we take into consideration that what zoos actually portray are creatures living outside their natural contexts, behaving in many cases in aberrant ways, walking in circles as if they were trying to dig their graves with their own steps. I agree with Gooding et al. (1997:27) that "we must return them all to their natural environments" with the necessary provisions, in order to provide them back their "sovereignty."

Another form of encapsulating nature has been the creation of National Primate Research Centers (Shapiro 2003). One of the earliest of these was created in Cayo Santiago, a small island off eastern of Puerto Rico. There, in the 1930's Clarence R. Carpenter set free around 400 rhesus macaques to analyze the ways in which these reorganized "naturally" in a new environment and the typical behaviors that developed in such situations. Interestingly enough, this led these monkeys to organize hierarchically by competitive aggression and, as noted by Harraway (1978b) and Sperling (1991), these similar attributes were later used to scientifically legitimize the beliefs of the 
naturalness of male dominance over women and of the aggressive appropriation and consumption of the other.

This caging of the other has not only been used for the non-human world but also for some of those "primitives" that live in the non-Western world. The most famous of these was the case of Ishi, the last Yahi survivor, who was brought by Berkeley anthropologists to a San Francisco museum and was put into display to demonstrate his primitive capacities of stone tool making, until he died of tuberculosis in 1916. This creation of a view of "animality" in the other was an intrinsic part of the development of anthropology and its use by the colonial powers to gain possession of their new territories (i.e., nature) and their inhabitants (i.e., animals) (Mullin 1999). In fact, when looked in these terms, the indigenous populations of most Western countries have been encased in limited territories defined as "reservations" which might be best regarded as "anthrozoos."

Another way of consuming the NHP other has been in their use in biomedical research, exploiting their bodies for exploring ways of mitigating imperfections in our biological design. This is another instance that reflects the discourse of colonization of nature and the human-based justifications that are devised in order to legitimize it. In fact, this use of the other as lab rats is in no way much different from the use of Puerto Rican women to test fertility pills in the 1960's (without knowing that they were being forming part of an experiment) by the United States government, which led to death of at least a dozen of them and the permanent infertility of many others.

The use of biomedical research using the other as the subject of study also provides another interesting instance that shows how the condition of alterity is manipulated in order to justify its exploitation. No case is clearer than that related to the transplantation of non-human organic matter (organs, blood, or cells) to humans (i.e. xenotransplantation). At the onset of medical experiments on this practice, NHP were the first to suffer their dismemberment to determine if their parts were fit to fix human medical problems due to the fact that these were the most comparable animals to us, although paradoxically the scientific promoters of this practice defended their technology by noting that they were still different enough from us to justify their consumption (Brown and Michael 2001). However, a public shift in opinion to one that advocated for a more intimate human (i.e., genetic and "cultural") relationship to NHP led to their later exclusion for their use for transplants because "they would be exposed to too much suffering" according to the Advisory Group on Ethics of Xenotransplantation (Keane and Ponsengarten 2002:272). Interestingly enough, they replaced NHP meat with that of the pig, "the other white meat," since no one would claim allegiance to the porcine lineage, but their organs were argued to be similar enough to ours to justify their medical consumption.

This emphasis on studying the other, in this case the NHP, for extracting biological capital to benefit ourselves is evident in the figures on the distribution 
of fields of study of primates provided by the American Society of Primatologists, which indicate that the vast majority (around 85 percent) of its active members are working in issues dealing with behavior, cognition, and communication (the last two being a minority), while only 15 percent of the people working in that field are actually engaged in any activity related to the conservation of those species (Shapiro 2003).

\section{Concluding Remarks}

As previously noted, anthropology has made use of the data generated from NHP in a similar fashion to that derived from the study of "traditional" societies: to better define the Western self by contrasting it to the other. As noted by Haraway (1978b:37), "we polish an animal mirror to look at ourselves," and that has been precisely the primary goal of anthropology and its use of primatology in the past.

Anthropologists and primatologists continue to argue about the boundaries between humans and the rest of the natural order, while at the same time they are often trespassing the other's boundary without their consent (Rees 2001). In trying to justify the incorporation of studies of NHP more deeply into the anthropological arena, Kinzey (1986) asked the questions of, what's in it for Anthropology? Unfortunately, there does not seem to be a proportional amount of people asking, what's in it for the other?

\section{Acknowledgements}

I want to thank Sue Boinski for motivating me to write this article. Thanks also to two anonymous reviewers for their comments. This material is based upon work supported under a National Science Foundation Graduate Research Fellowship.

\section{Literature Cited}

Addessi, E., M. Borgi, and E. Palagi. 2012. Is primatology an equal-opportunity discipline? PLoS ONE 7(1) (accessed online on April 4, 2014, at http://www.plosone.org/article/info\%3Adoi\%2F10.1371\%2Fjournal.pone.0030458.

Anderson, K. 1995. Culture and nature at the Adelaide Zoo: At the frontiers of human geography. Transactions of the Institute of British Geographers 20(3):275-294. http://dx.doi.org/10.2307/622652

Bailey, G. N. 1983.Concepts of Time in Quaternary Prehistory. Annual Review of Anthropology 12:165-192. http://dx.doi.org/10.1146/annurev.an.12.100183.001121

Batiste, S. L. 2012. Darkening Mirrors: Imperial Representation, Otherness and Subjectivity in African American Performance during the Repression Era. Duke University Press. Durham, North Carolina, USA. 352 pp. http://dx.doi.org/10.1215/9780822393757

Brown, N. and M. Michael. 2001. Switching between science and culture in transpecies transplantation. Science, Technology and Human Values 26(1):3-22. http://dx.doi.org/10.1177/016224390102600101

Dunnell, R.C. 1982. Science, social science, and common sense: The agonizing dilemma of modern archaeology. Journal of Anthropological Research 38(1):1-25.

Fabian, J. 1983. Time and the Other: How Anthropology Makes its Object. Columbia University Press. New York, NY, USA. 205 pp.

Fedigan, L. M. 1994. Science and the successful female: Why there are So many women primatologists. American Anthropologist 96(3):529-540. http://dx.doi.org/10.1525/aa.1994.96.3.02a00050 
Gooding, R. E., C. Pateman, and R. Pateman. 1997. Simian Sovereignty. Political Theory 25(6):821849. http://dx.doi.org/10.1177/0090591797025006003

Gosden, C. 2004. Archaeology and Colonialism: Cultural Contact from 5000 BC to the Present. Cambridge University Press. Cambridge, Massachusetts, USA. 187 pp.

Haraway, D. J. 1978a. Animal Sociology and a Natural Economy of the Body Politic, Part 1: A Political Phsychology of Dominance. Signs: Journal of Women in Culture and Society 4(1):2136. http://dx.doi.org/10.1086/493567

Haraway, D. J. 1978b. Animal sociology and a natural economy of the body politic, Part 2: The past is a contested zone: Human nature and theories of production and reproduction in primate behavior studies. Signs: Journal of Women in Culture and Society 4(1):37-60. http://dx.doi.org/10.1086/493568

Haraway, D. J. 1985. Primatology is politics by other means. PSA: Proceedings of the Biennal Meeting of the Philosophy of Science Association 2:489-524.

Haraway, D. J. 1989. Primate Visions: Gender, Race, and Nature in the World of Modern Science. Routledge. New York, NY, USA. 496 pp.

Haraway, D. J. 2003. The Companion Species Manifesto: Dogs, People, and Significant Otherness. Prickly Paradigm Press. Chicago, Illinois, USA. 100 pp.

Haraway, D. J. 2008. When Species Meet. University of Minnesota Press. Minneapolis, Minnesota, USA. 360 pp.

Hinde, R. 1978. Primate Studies and Anthropology. Royal Anthropological Institute News 28:1-4.

Islam, G. 2012. Can the subaltern eat? Anthropophagic culture as a Brazilian lens on post-colonial theory. Organization 19(2):159-180. http://dx.doi.org/10.1177/1350508411429396

Keane, H. and M. Posergarten. 2002. On the biology of sexed subjects. Australian Feminist Studies 17(39):261-277. http://dx.doi.org/10.1080/0957126022000018070

Khalidi, M. A. 1998. Natural kinds and crosscutting categories. The Journal of Philosophy 95(1):33-50. http://dx.doi.org/10.2307/2564567

Kinzey, W. G. 1986. New World primate studies: What's in it for Anthropology? Yearbook of Physical Anthropology 15:121-148.

Lizarralde, M. 2002. Ethnoecology of Monkeys among the Bari of Venezuela: Perception, Use, and Conservation. pp. 85-100. In, Primates Face to Face: The Conservation Implications of Human-Nonhuman Primate Interconnections. Fuentes, A. and L. D. Wolfe (Editors). Cambridge University Press. Cambridge, Massachusetts, USA. 360 pp.

Marcus, G. E. 1990. The Discourse of Primatology. Science 248(4957):886-887. http://dx.doi.org/10.1126/science.248.4957.886

McCray, C. A. 2012. Ota Benga under My Mother's Roof. Columbia. Simmonds. K. (Editor). University of South Carolina Press. Columbia, South Carolina, USA. 64 pp.

Mullin, M. H. 1999. Mirrors and Windows: Sociocultural studies of human-animal relations. Annual Review of Anthropology 28:201-224. http://dx.doi.org/10.1146/annurev.anthro.28.1.201

Murray, T. 1999. A return to the 'Pompeii Premise.' pp. 8-27. In, Time and Archaeology. Routledge. Murray, T. (Editor). New York, NY, USA. 172 pp.

Pagán-Jiménez, J. 2004. Is all archaeology at present a Postcolonial One? Answers from an eccentric point of view. Journal of Social Archaeology 4(2):200-213. http://dx.doi.org/10.1177/1469605304041075

Pagán-Jiménez, J. and R. Rodríguez Ramos. 2008. Towards the liberation of archaeological praxis in a "Postcolonial Colony:" The Case of Puerto Rico. pp. 53-71. In, Archaeology and the Postcolonial Critique. Liebman, M. and U. Z. Rizvi (Editors). Altamira Press. Lanham, Maryland, USA. 274 pp.

Rees, A. 2001. Anthropomorphism, anthropocentrism, and anecdote: Primatologists on Primatology. Science, Technology, and Human Values 26(2):227-247. http://dx.doi.org/10.1177/016224390102600205

Rodman, P. S. 1999 Wither Primatology? The Place of Primates in Contemporary Anthropology. Annual Review of Anthropology 28:311-339. http://dx.doi.org/10.1146/annurev.anthro.28.1.311

Schultz, A. H. 1955. Primatology in its relation to anthropology. Yearbook of Physical Anthropology 1955:47-60. 
Sperling, S. 1991. Baboons with Briefcases: Feminism, functionalism, and sociobiology in the evolution of primate gender. Signs 17(1):1-27. http://dx.doi.org/10.1086/494711

Stahl, A. B. 1993. Concepts of time and approaches to analogical reasoning in historical perspective. American Antiquity 58(2):235-260. http://dx.doi.org/10.2307/281967

Tringham, R. E. 1991. Households with Faces: The challenge of gender in prehistoric architectural remains. pp. 93-131. In, Engendering Archaeology: Women and Prehistory. Gero, J. M. and M. W. Conkey (Editors). Basil Blackwell. Oxford, England, UK. 436 pp.

Trouillot, M-R. 2003. Anthropology and the savage slot: the poetics and politics of otherness. In, Recapturing Anthropology: Working in the Present. Palmgrave McMillan. New York, NY, USA. 264 pp.

Wolf, J. 2002. Anima Urbis. Progress in Urban Geography 26(6):721-742. http://dx.doi.org/10.1191/0309132502ph400oa 